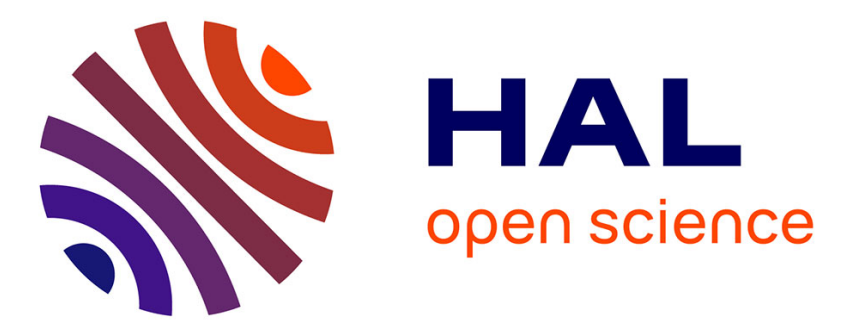

\title{
Further results on the relationship between the rate constants of o-Ps into p-Ps conversion and the electron delocalization in $3 \mathrm{~d}$ complexes
}

\author{
A. Fantola Lazzarini, E. Lazzarini, M. Mariani
}

\section{- To cite this version:}

A. Fantola Lazzarini, E. Lazzarini, M. Mariani. Further results on the relationship between the rate constants of o-Ps into p-Ps conversion and the electron delocalization in 3d complexes. Journal de Physique IV Proceedings, 1993, 03 (C4), pp.C4-113-C4-119. 10.1051/jp4:1993413 . jpa-00251456

HAL Id: jpa-00251456

https://hal.science/jpa-00251456

Submitted on 1 Jan 1993

HAL is a multi-disciplinary open access archive for the deposit and dissemination of scientific research documents, whether they are published or not. The documents may come from teaching and research institutions in France or abroad, or from public or private research centers.
L'archive ouverte pluridisciplinaire HAL, est destinée au dépôt et à la diffusion de documents scientifiques de niveau recherche, publiés ou non, émanant des établissements d'enseignement et de recherche français ou étrangers, des laboratoires publics ou privés. 


\title{
Further results on the relationship between the rate constants of o-Ps into $\mathrm{p}$-Ps conversion and the electron delocalization in $3 \mathrm{~d}$ complexes
}

\author{
A.L. FANTOLA LAZZARINI, E. LAZZARINI and M. MARIANI \\ Dipartimento Ingegneria Nucleare, CeSNEF, Politecnico di Milano, Via Ponzio 34/3, 20133 Milano, Italy
}

\section{SUMMARY}

The ortho into para-positronium conversion reactions promoted by the paramagnetic complexes formed with ethylenediaminetetraacetic acid ( $\mathrm{H}_{4} \mathrm{EDTA}$ ) by $\mathrm{Mn}$ (II), $\mathrm{Fe}$ (II), Co(II), Ni(II) ions were studied at various temperatures. The results are discussed together with those previously obtained for the $\mathrm{Cr}$ (III) and $\mathrm{Cu}$ (II) complexes with the same ligand. It was found that the rate constants, $\mathrm{k}_{\mathrm{SE}}$, are larger for complexes: A) whose $3 \mathrm{~d}$ inter-electronic repulsion parameter attains smaller values; and B) for which spin orbit coupling occurs. These findings give further support to our proposal that the o-Ps into p-Ps conversion reaction may be used to investigate the electron delocalization in paramagnetic 3d complexes.

\section{INTRODUCTION}

Ps atoms may undergo several types of chemical reaction, among them the conversion reaction (SE), which consists of O-Ps being converted into p-Ps atoms (and vice versa) by interacting with paramagnetic species.

Recently, we have found that the rate constants $k_{S E}$ of o-Ps into $\mathrm{p}$-Ps conversion reactions promoted by $\mathrm{Fe}_{\mathrm{aq}}^{2+} ; \mathrm{Co}_{a q}^{2+} ; \mathrm{Ni}_{\mathrm{aq}}^{2+}$ and $\mathrm{Cu}_{\mathrm{aq}}^{2+}$ aquaions are twice as large as those of the $\mathrm{Cr}_{\mathrm{aq}}^{3+}$ and $\mathrm{Mn}_{\mathrm{aq}}^{2+}$ ions $(\sim 2.0$ against - $\left.1 \mathrm{M}^{-1} \mathrm{~ns}^{-1}\right)^{1}$. It should be noted that the magnetic moments $\mu_{\text {eff }}$ of the first four ions are of the soc type (SOC $=$ spin orbit coupling), while those of $\mathrm{Cr}_{a q}^{3+}$ and $\mathrm{Mn}_{a q}^{2+}$ are of the spin only (SO) type.

The explanation advanced is based on the fact that the $k_{\mathrm{SE}}$ values of the o-Ps to p-Ps conversion reactions promoted by $4 f, 3 d$ aqua ions 
and the ammoniated electron increase in the order $k_{S E}(4 f)^{2} \ll k_{S E}(3 d)$ 《 $\mathrm{k}_{\mathrm{SE}}\left(\mathrm{e}_{\mathrm{am}}^{-}\right)^{3},\left(0.05: c a, 2: 50 \mathrm{M}^{-1} \mathrm{~ns}^{-1}\right)$. That is, $\mathrm{k}_{\mathrm{SE}} \mathrm{s}$ seem to increase as the spin density of the unpaired electrons increases at the collision site between the ion and Ps atom. Consequently, it was argued that the delocalization of the unpaired metal electron (and consequently the $\mathrm{k}_{\mathrm{SE}}$ ) should be larger when SOC occurs. Details may be found in ref. 1 .

Subsequently, a systematic investigation carried out on 14 CI(III) complexes, has ascertained that the $\mathrm{k}_{\mathrm{SE}}$ s are also correlated with the corresponding $\beta$ ratios between the inter-electronic repulsion parameter of the complex, $B$, and that of the free gaseous ion, $\mathrm{B}_{0}{ }^{4}$. We recall that the $\beta$ values are less than 1 and different for the various complexes. This means that the $3 \mathrm{~d}$ inter-electronic repulsion is less in complexes than in the free gaseous ion due to the expansion of the $3 d$ electron cloud of the metal ion towards the ligand donor ${ }^{5}$. The experimental results show indeed that $k_{S E}$ increases as the $\beta$ value decreases.

Continuing our work, the $k_{\mathrm{SE}}$ s of the $\mathrm{Mn}$ (II); Fe(II); Co(II) and $\mathrm{Ni}(\mathrm{II})$ complexes with the ethylenediaminetetraacetic acid ( ${ }_{4} \mathrm{EDTA}$ ) ligand were measured. The results are here described and discussed with those of the same $\operatorname{Cr}\left(\right.$ III) ${ }^{4}$ and $\mathrm{Cu}(\text { II })^{6}$ complexes already measured.

The measurements were made at different temperatures in order to ascertain whether the reactions were diffusion controlled (DCR) as are those occurring between Ps and the $\mathrm{Cr}$ (III) and $\mathrm{Cu}$ (II) complexes already investigated.

\section{EXPERIMENTAL}

Materials.- The complexes were prepared according to the literature ${ }^{7,8}$. Their formulae in aqueous solutions are $\left[\mathrm{M}^{\mathrm{II}}(\mathrm{EDTA}) \mathrm{H}_{2} \mathrm{O}^{2-}\right.$, but while the $\mathrm{EDTA}^{4-}$ ion behaves as a pentadentate Iigand for $\mathrm{Fe}(\mathrm{II}), \mathrm{Co}(\mathrm{II}), \mathrm{Ni}(\mathrm{II}), \mathrm{Cr}(\mathrm{II})$ and $\mathrm{Cu}(\mathrm{II})$, by contrast it is hexadentate in Mn(II) complex, which therefore is a heptacoordinate ${ }^{9}$. The rate constants were derived from PAI (Positron Annihilation Lifetime) spectroscopy. A conventional fast-fast coincidence system already described was used ${ }^{1}$. The PAL spectra were decomposed into three components by using the POSITRONFIT program ${ }^{10}$; no constraint for the component intensities and lifetimes was imposed.

The rate constants of o-Ps into $\mathrm{p}-\mathrm{Ps}$ conversion were calculated by 
means of Eqn(1) which relates the decay constant, $\lambda$, of the long lived component of the PAL spectra to the decay constant $\gamma=\mathrm{k}_{\mathrm{SE}} \mathrm{c}$ of the o-Ps into p-Ps conversion reaction, $c$ being the solute concentration:

$$
\lambda=2 \gamma+\frac{\lambda_{\mathrm{s}}+\lambda_{\mathrm{t}}}{2}+\lambda_{\mathrm{pO}}-\left[3 \gamma^{2}+\left(\gamma+\frac{\lambda_{\mathrm{s}}-\lambda_{\mathrm{t}}}{2}\right)^{2}\right]^{1 / 2}
$$

$\lambda_{s}$ and $\lambda_{t}$ are the p-Ps and o-Ps intrinsic decay constants in aqueous solution $\left(6.4 \text { and } 0.0057 \mathrm{~ns}^{-1}\right)^{1}$, and $\lambda_{\mathrm{po}}$ is the decay constant by pick off, also in aqueous solution. It was assumed that $\lambda_{P 0}$ is independent of $c$ and equal for both o-Ps and $p-P s$ atoms. In pure water its value is $0.540 \pm 0.005 \mathrm{~ns}^{-1}$.

$\gamma$ values, deduced from the $\lambda$ values (eqn.(1)), were normalized to the pure $\mathrm{H}_{2} \mathrm{O}$ viscosity by multiplying them by the $\eta(\mathrm{C}) / \eta\left(\mathrm{H}_{2} \mathrm{O}\right)$ ratio ${ }^{1}$ where $\eta\left(\mathrm{H}_{2} \mathrm{O}\right)$ is the viscosity coefficient of pure water and $\eta(\mathrm{C})$ that of the solution at concentration $c$. Finally, $k_{\mathrm{SE}}$ was deduced from the slope of the straight line interpolating the $\gamma$ values vs. $c$.

Assignment of Reaction Type. - The reactions of o-Ps atoms with our $\mathrm{H}_{4} \mathrm{EDTA}$ complexes are of the $\mathrm{SE}$ type, as it was ascertained by means of the Doppler Broadening of Annihilation Radiation (DBAR) spectra. These experiments were carried out at room temperature $\left(22 \pm 1^{\circ} \mathrm{C}\right)$.

Our DBAR spectrometer was equipped with a planar HPGe detector $\left(200 \mathrm{~mm}^{2} \times 10 \mathrm{~mm}\right)$ supplied by ORTEC. The FWHM (Full Width at Half Maximum), $\Delta \mathrm{W}_{\gamma}$, for the $496 \mathrm{keV} \gamma$ ray emitted in the ${ }^{103} \mathrm{Ru}$ decay is $0.94 \mathrm{keV}$, while that of the overall annihilation peak $\Delta W_{A n}$ in pure water is $2.52 \mathrm{keV}$.

The AR curves were decomposed into four Gaussian components by using the ACARFIT program ${ }^{11}$ and applying as constraints the FWHMs, $\Delta W_{1}$, of the various annihilation modes. We recall here that while the ratio between $\mathrm{O}-\mathrm{Ps}$ and $\mathrm{p}-\mathrm{Ps}$ formation probabilities $\mathrm{P}_{\mathrm{o}-\mathrm{Ps}} / \mathrm{P}_{\mathrm{p}-\mathrm{Ps}}$ is 3 , that between the corresponding intensities $I_{0-P s}$ and $I_{p-P s}$ of annihilation radiation is 3.3 due to p-Ps annihilations by pick off.

The $I_{p-P s}(c)$ in converter solution at concentration $c$ is given by eqn. (2):

$$
\frac{I_{p-P s}(c)}{P_{p-P s}(0)}=\left[\frac{\lambda_{s}\left(\lambda_{t}+\lambda_{P O}+4 k_{S E} c\right)}{k_{S E} c\left(\lambda_{s}+3 \lambda_{t}+4 \lambda_{P O}\right)+\left(\lambda_{t}+\lambda_{P O}\right)\left(\lambda_{s}+\lambda_{P O}\right)}\right]
$$

where $\mathrm{p}_{\mathrm{p}-\mathrm{Ps}}, \lambda_{\mathrm{s}, \mathrm{t}}, \lambda_{\mathrm{PO}}, \mathrm{k}_{\mathrm{SE}}$ have been already defined. 
Solutes may also cause inhibition of Ps formation. Several equations have been suggested for relating $I_{P s}(c)$ to the solute concentration $12,13,14$. In many cases the following empirical equation may be safely used up to $c=1-1.5 \mathrm{M}$ :

$$
P_{P s}(c) / P_{P s}(0)=(1-f)+f /(1-K c)
$$

where $K\left(\right.$ in $\mathrm{M}^{-1}$ ) is the inhibition constant dependent on the solute type and $f$ is the maximum inhibition fraction, also dependent on solute and solvent.

Consequently, if the paramagnetic species also promotes inhibition of Ps formation, the right side of Eqn.(2) should be multiplied by the right side of $\operatorname{Eqn}(3)$.

\section{RESULTS}

In order to ascertain whether the reactions were $\mathrm{DC}$, the $\mathrm{k}_{\mathrm{SE}}$ values of each complex were analyzed according to a procedure already described $^{1}$. It was found that this is so. For the sake of conciseness we given here only the $\mathrm{k}_{\mathrm{SE}}^{298} \mathrm{~s}$ at $298 \mathrm{~K}$ (Table 1 ).

\section{TABLE 1}

The $k_{\mathrm{SE}}$ in $\mathrm{M}^{-1} n \mathrm{~s}^{-1}$ at $298 \mathrm{~K}$ of $\mathrm{O}-\mathrm{Ps}$ into $p-P S$ conversion reactions promoted by aqua and $H_{4} E D T A$ complexes of named metal ions are shown. Their $\beta$ values are also given when available. Even if unknown, the $\beta$ values of $\mathrm{H}_{4}$ EDTA complexes are larger than those of the corresponding aqua ions. The type of magnetic moment is also mentioned. (details in the text).

\begin{tabular}{|l|c|c|c||c|c|c|}
\hline Ion & $\begin{array}{l}\mathrm{k}_{\mathrm{SE}} \text { of aqua } \\
\text { ions ref.1 }\end{array}$ & $\begin{array}{c}\text { Spin } \\
\text { ref.15 }\end{array}$ & $\begin{array}{c}\mathrm{k}_{\mathrm{SE}} \text { of } \mathrm{H}_{4} \text { EDTA } \\
\text { orbit } \\
\text { compling? }\end{array}$ & $\begin{array}{c}\beta \\
\text { ref.15in } \\
\text { orbit } \\
\text { coupling? }\end{array}$ \\
\hline $\mathrm{Cr}(\mathrm{II})$ & $1.01 \pm 0.09$ & 0.79 & No & $1.42 \pm 0.02$ & 0.75 & No \\
$\mathrm{Mn}(\mathrm{II})$ & $1.01 \pm 0.06$ & 0.930 & No & $1.06 \pm 0.03$ & 0.916 & No \\
\hline $\mathrm{Fe}(\mathrm{II})$ & $2.26 \pm 0.02$ & - & Yes & $3.01 \pm 0.06$ & - & Yes \\
$\mathrm{Co}(\mathrm{II})$ & $2.16 \pm 0.12$ & 0.76 & Yes & $2.41 \pm 0.05$ & 0.71 & Yes \\
$\mathrm{Ni}(\mathrm{II})$ & $2.58 \pm 0.03$ & 0.88 & Yes & $3.15 \pm 0.15$ & 0.85 & Yes \\
$\mathrm{Cu}(\mathrm{II})$ & $\sim 1.6$ & - & Yes & $\sim 2.4$ & - & Yes \\
\hline
\end{tabular}


The results of DBAR measurements may be summarized as follows. The AR peaks of all complexes may be decomposed into four components, which were ascribed to $\mathrm{p}-\mathrm{Ps}, \mathrm{O}-\mathrm{Ps}$, free $\mathrm{e}^{+}$and annihilations in the source mounting (48).

The variances of the final fits ranged between $0.85-1.20$ for $65-70$ degrees of freedom and the experimental and back-calculated $\Delta W_{A n}$ values agreed within experimental error $( \pm 0.02 \mathrm{keV})$.

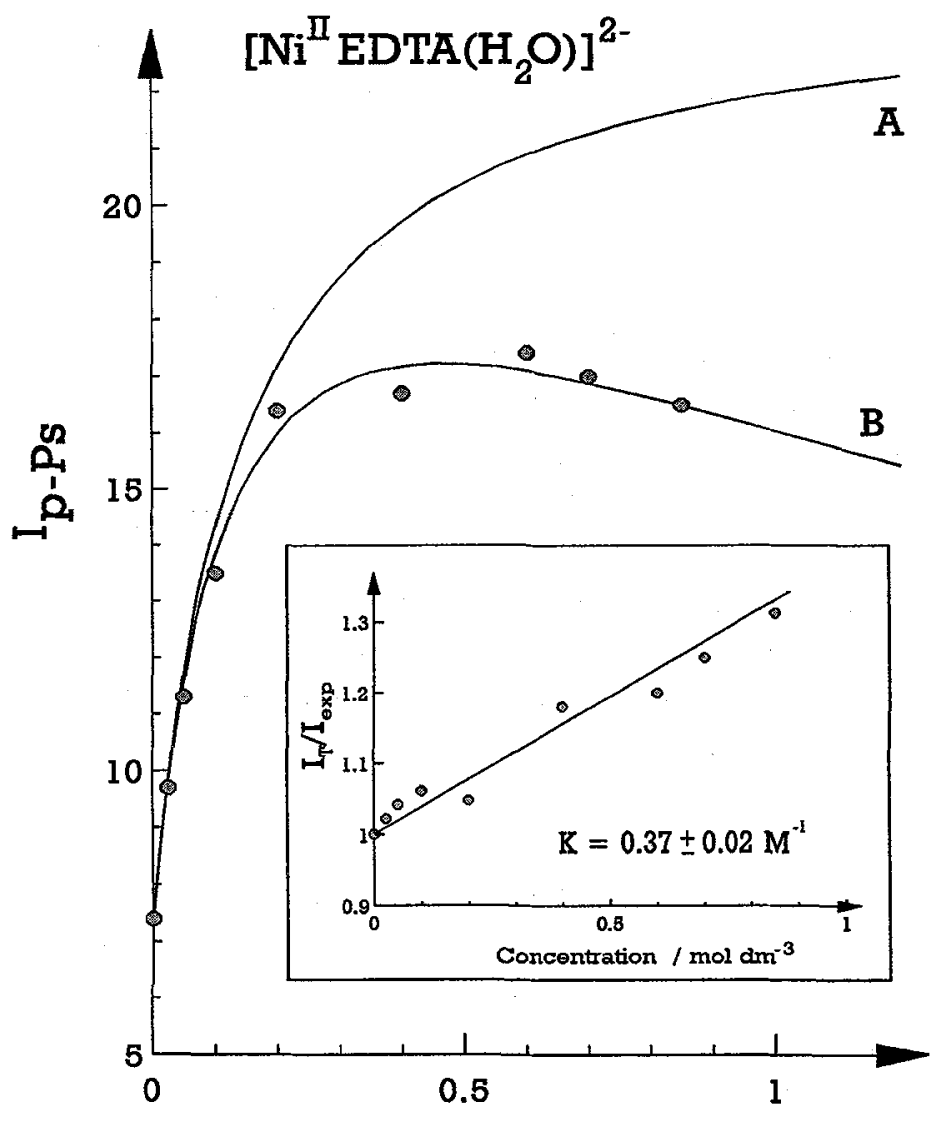

Concentration / $\mathrm{mol} \mathrm{dm}{ }^{-3}$

FIG.1 - The points are the experimental $I_{\mathrm{p}-\mathrm{Ps}}(C)$ values of $\left[\mathrm{Ni}(\mathrm{EDTA}) \mathrm{H}_{2} \mathrm{O}\right]^{2-}$ complex. Curve $B$ is the plot of the theoretical intensity, $I_{\mathrm{T}}$, vs. $C$ (Eqn. 2$)$ at $22.5^{\circ} \mathrm{C}\left(\mathrm{k}_{\mathrm{SE}}=3.1\right.$ $M^{-1} n S^{-1}$ ) assuming that $P S$ inhibition does not occur, while curve $A$ takes into account inhibition of PS formation (Eqn. 3 with $f=0$ and $k=0.37 \pm 0.02$ ). The plot of Eqn. 3 from which the $f$ and $K$ values were deduced, is shown in the insert. 
The experimental trend of $I_{p-p s}$ vs. $C$ is similar for all the complexes investigated, (see e.g. fig.1, curve A). The expected trend of $I_{T}(C)$ calculated at $22.5^{\circ} \mathrm{C}$ with Eqn.(2) is given by the curve $B$ of the same figure, that is in all cases the calculated intensities $I_{T}(c)$ were found to be bigger than the experimental ones. Thus it was hypothesized that the complexes are also inhibitors of Ps formation. The inhibition constants $K$ were obtained by means of eqn(3).

It was found that the complexes investigated are total inhibitors of Ps formation and that their inhibition constants are as follows:

$$
\begin{array}{ll}
\mathrm{K}[\mathrm{Mn}(\mathrm{II})]=0.11 \pm 0.01 & \mathrm{~K}[\mathrm{Fe}(\mathrm{II})]=0.21 \pm 0.02 \\
\mathrm{~K}[\mathrm{Co}(\mathrm{II})]=0.12 \pm 0.01 & \mathrm{~K}[\mathrm{Ni}(\mathrm{II})]=0.37 \pm 0.02
\end{array}
$$

The extrapolation of the experimental $I_{p-P s}(c)$ values vs. $c$ obtained by inserting Eqn.(3) in Eqn.(2) and by using the $k_{S E}$ and $k$ values given above is rather good (curve $A$ of Fig. 1).

Finally it may be concluded that:

A) the four reactions investigated are DCRs as those promoted by the two complexes $\left[\mathrm{Cr}(\mathrm{EDTA}) \mathrm{H}_{2} \mathrm{O}\right]^{-}$and $\left[\mathrm{Cu}(\mathrm{EDTA}) \mathrm{H}_{2} \mathrm{O}\right]^{2-}$ previously studied;

B) the complexes studied promote the o-Ps into p-Ps conversion reaction and inhibition of Ps formation.

In order to simplify the following discussion the $k_{5 E}$ of the aquaions were also collected in Table 1 .

\section{DISCUSSION}

The main conclusions reached may be summarized as follows:

A) the trend of the $\mathrm{k}_{\mathrm{SE}}^{298} \mathrm{~s}$ of the $\mathrm{H}_{4} \mathrm{EDTA}$ complexes parallels that of the $\mathrm{k}_{\mathrm{SE}}^{298} \mathrm{~s}$ of the aqua-ions. That is, the $\mathrm{k}_{\mathrm{SE}}^{298} \mathrm{~s}$ of complexes, whose $\mu_{\text {eff }}$ is of so type, are smaller than those of the complexes for which $\mu_{e f f}$ is of the SOC type;

B) the $\mathrm{k}_{\mathrm{SE}}^{298}$ values of the $\mathrm{H}_{4} \mathrm{EDTA}$ complexes are generally larger than those of the corresponding aqua-ions. In fact the $\beta$ values of aqua ions are larger than those of the ${ }_{4}$ EDTA complexes. The rather similar $\mathrm{k}_{\mathrm{SE}}^{298}$ values of the two $\mathrm{Mn}(\mathrm{II})$ complexes may, indeed, be justified by the fact that the $\beta$ values of $\mathrm{Mn}$ (II) complexes are very similar to each other ${ }^{15}$. Moreover, it cannot be disregarded that while $\mathrm{Mn}_{\mathrm{aq}}^{2+}$ ion is hexacoordinate, the $\left[\mathrm{Mn}(\mathrm{EDTA}) \mathrm{H}_{2} \mathrm{O}^{2-}\right.$ complexes is heptacoordinated. This causes an increase of the bond lengths with a consequent possible increase of the $\beta$ value of the EDTA $^{4-}$ complex with respect to that of $\mathrm{Mn}_{\mathrm{aq}}^{2+}$. On the contrary, we 
have no sure explanation at the moment for the small difference between $k_{\mathrm{SE}}\left[(\operatorname{COEDTA})^{2-}\right]$ and $\mathrm{k}_{\mathrm{SE}}\left[\mathrm{Co}_{\mathrm{aq}}^{2+}\right]$.

In conclusion the first statement confirms the role of $\mathrm{SOC}$ in delocalization of the unpaired metal electrons and the second supports, or at least does not contradict, the statement that $k_{\mathrm{SE}}$ increases as the $3 d$ electron cloud expands towards the donor atoms and the complex periphery.

\section{REFERENCES}

1) A.L.Fantola Lazzarini and E.Lazzarini, struct.Chem., 2, 409, (1991)

2) A.Bisi, G.Consolati, L.Zappa, Can. J. Phys., 64, 1379 (1986)

3) A.Bisi, L.Bosi, E.Lazzarini, L.zappa, J. Chem. Phys., 63, 5087 (1975)

4) A.L.Fantola Lazzarini, E.Lazzarini, Struct.Chem., 3, 407, (1992)

5) F.A.Cotton, G.Wilkinson, Advanced Inorganic Chemistry, Interscience $1^{\text {st }}$ ed. New York, 1962, pp.506-507

6) De Natale, A.Dupasquier, A.I.Fantola Lazzarini, E.Lazzarini, A.Rolando, Mat. Sci.Forum, 105-110, 1537 (1992).

7) "Inorganic Synthesis", Eds T.Moeller, vol.5, MacGraw-Hill Book, New York 1957, p.186.

8) G.S.Smith, J.L.Hoard, J.Am.Chem.Soc., 81, 556, (1959)

9) S.Richard, B.Pedersen, J.V.Silveston, J.L.Hoard "Inorg. Chem.", 3, 27 (1964)

10) M.Eldrup, Report $N^{\circ} 254$, Risø, 1971

11) P.Kirkegaard, M.Eldrup, Report Risø - M - 1400, Risø, 1971

12) A.Foglio Para, E.Lazzarini, J.Inor. Nucl. Chem., 42, 475 (1980)

13) E.Lazzarini, Radiat. Phys. Chem. , 28, 49 (1986)

14) Y.Ito, E.Lazzarini ad H.J.Ache in "Handbook of Hot Atom Chemistry", Eds. J.P.Adloff et al., VCH, New York, 1992, p.488.

15) B.N.Figgis "Introduction to Ligand Fields" Interscience, New York, 1966, p. 244 